IN MEMORIAM 



\section{Juan Pegueroles Moreno (1928-2019)}

Conocí al profesor Juan Pegueroles en los últimos años de la década de los setenta, en la Universidad de Deusto, donde impartía clases de Historia de la Filosofía. Acababa de terminar mis estudios de Filosofía en la Universidad de Navarra y me trasladé a Bilbao donde redactaba mi tesina como trabajo previo al doctorado. La temática de la misma era El hombre como imagen de Dios en san Agustín. En la Biblioteca Loyola de la Universidad de Deusto, a la que acudía regularmente por su excelente biblioteca, me hablaron del profesor Pegueroles al que consideraban como uno de los mejores conocedores de la filosofía agustiniana. De modo inmediato, concerté con él una cita y conversamos sobre nuestro filósofo Agustín de Hipona. Desde ese primer encuentro, comenzó nuestra amistad filosófica y espiritual que ha durado cuarenta años, hasta su muerte acaecida el 28 de marzo de este año 2019 en san Cugat del Vallès (Barcelona). Desde el primer momento lo consideré como mi maestro y profesor. Así me dirigía a él en las cientos de cartas, correos electrónicos, llamadas y visitas. Él, a su vez, y sin haberme dado nunca clases me consideró siempre como su alumna. De ese modo me presentaba cuando iba a verlo en mi visita anual al Centre Borja. Muchas personas, he de decir, acudíamos a visitarle en busca de una orientación filosófica y humana. Él siempre estaba dispuesto a recibirnos y a transmitirnos su sabiduría que siempre fue abundante.

¿Cómo podría definir al profesor Pegueroles? Robándole las palabras a otro buen amigo suyo, el profesor Eudaldo Forment: «Como un hombre santo y un sabio humilde». Así lo era. El profesor Juan Pegueroles vivió con profundidad y alegría su vocación filosófica y espiritual como jesuita. Era un hombre abierto, tanto a la filosofía clásica como a la moderna y contemporánea. ¡Cuántas veces me repetía!: «Por mi parte, estoy convencido de que todo gran filósofo, como todo gran artista, es un verdadero don de Dios a los hombres». Nos enseñaba a estar a la escucha y descubrir tesoros de verdades en distintas filosofías. Me enseñó mucho sobre san Agustín y, abierto, como estaba a otros pensadores, me introdujo en la filósofa Simone Weil a la que sigo leyendo y estudiando. Quiero traer aquí las palabras del propio profesor Pegueroles que escribió a propósito de sus veinte años en la dirección de la revista Espíritu. Creo que son las que mejor nos descubren su personalidad filosófica. «Mis primeros veinte años de docencia de la Historia de la Filosofía (iniciada en 1961) los pasé acompañado por san Agustín, que es como decir acompañado por Platón. La participación en el Ser, en la Verdad y en el Bien, por parte del hombre, fue mi primer descubrimiento filosófico, mi primera verdad personal. Que Dios entra, como dice Scheler, en la definición del hombre. En los últimos quince años, descubrí, mejor dicho, fui sorprendido (porque fue una auténtica e inesperada sorpresa) por la fenomenología de Husserl y el pensamiento de Heidegger, sobre todo en su punto de confluencia que es Gadamer. Así que primero fue el descubrimiento del absoluto de la verdad y del bien, después el descubrimiento de la historicidad del conocimiento de la verdad y del bien. Primero fue el descubrimiento del infinito del espíritu humano, después el de la finitud (histórica y lingüística) de este espíritu, es decir, que 
el hombre está finitamente abierto al infinito en un proceso sin fin». (Espíritu, 48 (1999), pp. 173-179).

Su intenso amor y dedicación a la filosofía, le llevó a publicar no menos de noventa artículos y cinco libros. Entre estos últimos, quiero destacar el siguiente: San Agustín. Un platonismo cristiano (Colección Biblioteca Universitaria de Filosofía 5, Edit. PPU, Barcelona 1985, 275 pp). La mayoría de los artículos que escribió lo hizo sobre filosofía agustiniana. En especial, quiero señalar algunos que dedicó a la libertad en san Agustín. Nos enseñó que la libertad, tal y como la concibe Agustín, consiste en hacer el bien y en no poder hacer el mal. Y, esta concepción de la misma, es clave para estar cerca de Dios y poder ser felices. Así lo desarrolló en artículos como: «La libertad para el bien en san Agustín», en Espíitu 23 (1974), pp. 101-106; Postscriptum. «La libertad como necesidad del bien en san Agustín», en Espíritu, 37 (1988), pp. 153-156; y este último, «Libertas, fin del liberum arbitrium en san Agustín», en Augustinus, 39 (1994), pp. 365-371. Estoy convencida de que es el que mejor entendió la libertad agustiniana.

Otro bloque importante de artículos se refiere a la Hermenéutica. Todavía recuerdo sus comentarios cuando iba descubriendo a Gadamer. Entre ellos, quiero resaltar los siguientes: «La revolución hermenéutica de H.G. Gadamer», en Espíritu, 45 (1996), pp. 173182; «La hermenéutica de Gadamer y la desconstrucción de Derrida», en Pensamiento, 55 (1999), pp. 483-490 y «Platón reinterpretado: la nueva representación. El último capítulo de Verdad y Método», en Espíritu, 48 (1999), pp. 31-38. Uno de sus autores favoritos, cuyo Diario leía en la traducción italiana hecha por Cornelio Fabro, era Kierkegaard. Leía y releía a este filósofo. En sus artículos sobre el filósofo danés, aparecen de nuevo los temas a los que más tiempo dedicó: la libertad, Dios, el bien, la verdad y la angustia. Así voy a nombrar: «Amor, sufrimiento y alegría. Dios en el Diario de Kierkegaard», en Pensamiento, 56 (2000), pp. 477-489; «La Libertad y el bien, la libertad y la verdad, en El concepto de la angustia, de Kierkegaard», en Espíritu, 49 (2000), pp. 77-83 y «La insoportable grandeza del hombre en el cristianismo», según Kierkegaard. Algunos textos del diario, en Espíritu, 51 (2002), pp. 5-9.

En el haber del profesor Pegueroles hay también una bibliografía de artículos referidos a autores diversos, a la que podemos situar entre los varios. Allí abundan tanto filósofos como literatos: «Estructura general y dialéctica interna de L'Action (1893) de Blondel» en Pensamiento, 27 (1971), pp. 181-214; «Moral del bien y moral de la ley. Kant y Santo Tomás» en Espíritu, 33 (1984), pp. 17-26; «El ser y el sentido. Notas husserlianas» en Espíritu, 35 (1986), pp. 63-70 y por último «El socialismo ateo y el socialismo cristiano en el Diario de un Escritor de Dostoyeski», en Actualidad bibliográfica, 17 (1080), pp. 3470. Por último, una serie de escritos, artículos o apuntes inéditos como aquellos que nos enviaba a los amigos por correo electrónico o nos los daba en páginas escritas. Un auténtico regalo: «Presentación de Péguy. Las obras en prosa de 1910 a 1914»; «La concepción cristiana de la justicia y de la pobreza. Los últimos escritos de G. Bernanos»; «Nuestros amigos los santos. El testamento de Bernanos»; «Los presupuestos fenomenológicos de la hermenéutica de Gadamer» y «De mis lecturas». Vivía compartiendo sus 
conocimientos con profesores, alumnos y amigos. Todavía guardo algunas de las carpetas que me regaló con fotocopias y anotaciones que había hecho de san Agustín de Hipona, Edith Stein y de otros temas. Su escritura era clara y concisa, sin perderse nunca en divagaciones estériles. Es hora de volver a aprender del maestro, ya no oyéndole a él pero sí releyendo sus escritos.

Nombrando sólo unos pocos artículos, como hemos hecho, podemos comprobar que los intereses filosóficos del profesor Pegueroles eran muy amplios: San Agustín de Hipona, Santo Tomás de Aquino, Kierkegaard, Husserl, Gadamer, Berdiaev, Scheler, Simone Weil, Edith Stein...Y también sus intereses literarios. Lector apasionado, tenía especial devoción por Dostoyevsky, Newman, Péguy, Bernanos, Guardini, Santa Teresa de Ávila, San Juan de la Cruz, Lewis, Jiménez Lozano y tantos otros. Cuando su mente estaba ya muy cansada, leía novelas policíacas y cómics como los de Tintín en el país de los soviets, a los que siempre les sacaba su jugo filosófico. Una vida interior llena de conocimientos y de experiencias.

Todos los años iba a visitarle con una amiga que le apreciaba mucho, Luz Marina. Nos acercábamos al Centre Borja en san Cugat del Vallès. La última visita que le hicimos, fue en el mes de octubre. Acababa de cumplir 90 años, una década especial y le llevamos varios libros de regalo. Siempre agradecido, nos dedicó más de una hora transmitiéndonos sus últimas lecturas y reflexiones. Justo cuando nos estábamos despidiendo, nos miró y nos dijo: «Hasta el año próximo o hasta la eternidad». Nunca olvidaremos este último encuentro. Descanse en paz y siga ayudándonos a sus alumnos y compañeros del mundo de la Filosofía. Aunque muchos nos sentimos huérfanos sin él, nos quedan sus escritos, su dedicación y esa sonrisa con la mirada viva y alegre de quien siempre supo transmitir un conocimiento filosófico o espiritual.

MARÍA DEL CARMEN DOLBY MÚGICA Universidad Nacional de Educación a Distancia 
